\title{
Interference resolution: Insights from a meta-analysis of neuroimaging tasks
}

\author{
Derek Evan NeE \\ University of Michigan, Ann Arbor, Michigan \\ TOR D. WAGER \\ Columbia University, New York, New York \\ AND \\ JOHN JONIDES \\ University of Michigan, Ann Arbor, Michigan
}

\begin{abstract}
A quantitative meta-analysis was performed on 47 neuroimaging studies involving tasks purported to require the resolution of interference. The tasks included the Stroop, flanker, go/no-go, stimulus-response compatibility, Simon, and stop signal tasks. Peak density-based analyses of these combined tasks reveal that the anterior cingulate cortex, dorsolateral prefrontal cortex, inferior frontal gyrus, posterior parietal cortex, and anterior insula may be important sites for the detection and/or resolution of interference. Individual task analyses reveal differential patterns of activation among the tasks. We propose that the drawing of distinctions among the processing stages at which interference may be resolved may explain regional activation differences. Our analyses suggest that resolution processes acting upon stimulus encoding, response selection, and response execution may recruit different neural regions.
\end{abstract}

The need to select information among competing alternatives is ubiquitous. Oftentimes, successful cognition depends on the ability to focus resources on goal-relevant information while filtering out or inhibiting irrelevant information. How selective attention operates and whether and how irrelevant information is inhibited or otherwise filtered out has been a major focus of research since the inception of experimental psychology. For the past 15 years, cognitive neuroscientists have used neuroimaging to uncover the brain mechanisms underlying the processes responsible for handling irrelevant information. Much of this research has used variants of classic cognitive interference resolution tasks, each different in its superficial characteristics but sharing the common requirement to resolve conflict. What have we learned from this large corpus of data?

Examining the multitude of studies focusing on interference resolution tells an extremely varied story. Figure 1A shows a plot of the peaks of activation of 47 studies that purport to examine interference resolution (see the studies listed in Table 1). Ostensibly, there appears to be little consistency in these data. Several factors may be contributing to the massive interstudy variance. First, Figure 1A includes activations from different tasks, subjects, equipment, scanning parameters, and statistical analyses. If we constrain our focus to just one task, however, the activations do not appear to be much more consistent. Figure 1B shows the activations arising just from the Stroop task (Stroop, 1935), and these do not appear any more orderly. Indeed, the variability among the reported peaks across all interference resolution tasks corroborates behavioral findings that correlations in performance among different interference resolution tasks are low (Kramer, Humphrey, Larish, Logan, \& Strayer, 1994; Shilling, Chetwynd, \& Rabbitt, 2002). Indeed, even simple changes in task parameters appear to produce very different results (e.g., de Zubicaray, Andrew, Zelaya, Williams, \& Dumanoir, 2000; MacLeod, 1991). It seems clear that understanding interference resolution will take deeper analytic methods that interrogate possible strategic and mechanistic differences. Some researchers have attempted to examine the neural signatures of various interference resolution tasks within the same subjects to uncover whether any consistency can be found (Fan, Flombaum, McCandliss, Thomas, \& Posner, 2003; Liu, Banich, Jacobson, \& Tanabe, 2004; Peterson et al., 2002; Wager et al., 2005). These efforts have revealed that activations in different tasks overlap in a number of regions but that there are also regions unique to one task or another. What underlies these commonalities and differences?

At this point, there have been a sufficient number of studies of interference resolution to begin to answer these questions. Here, we will attempt to sift through the inter-

D. E.Nee, dnee@umich.edu 

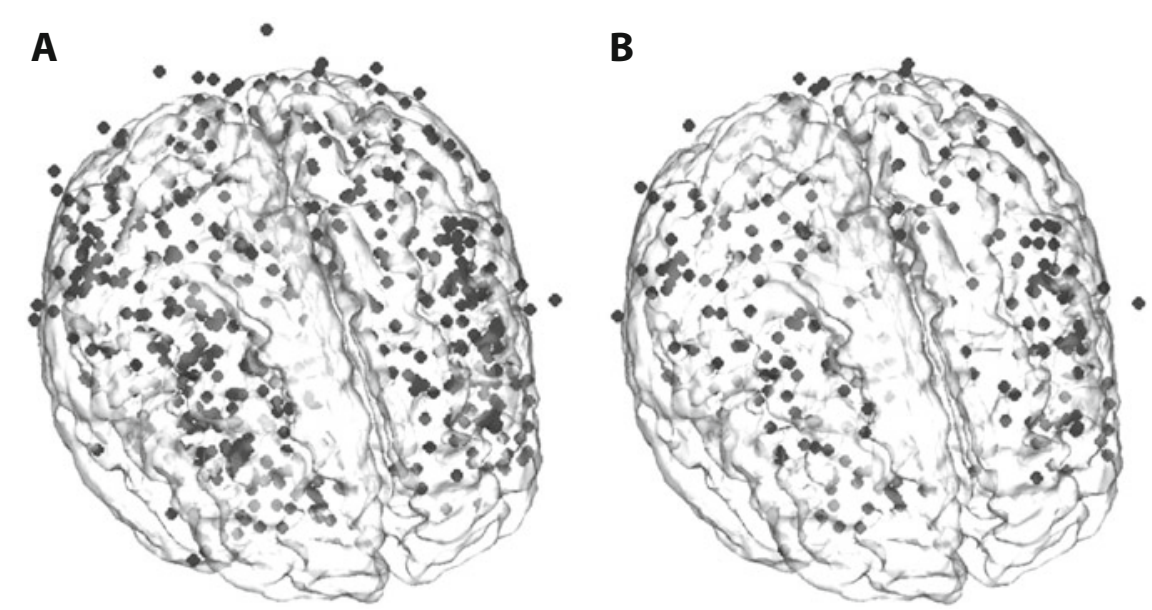

Figure 1. (A) Peaks from the 47 studies included in the meta-analysis, plotted in a single brain. (B) Peaks from the studies in which the Stroop task was used. ${ }^{1}$

study variance in the interference resolution literature and pick out the consistencies among studies and tasks. In addition to trying to uncover the neural basis of interference resolution, we shall also consider why variations in tasks and task parameters may lead to separable patterns of neural activation. Although the meta-analytic methods used here preclude us from drawing strong conclusions about interference resolution (because they rely on reported peak coordinates from previous studies), they allow us to begin to form hypotheses that further investigations can either confirm or deny (e.g., Fox, Laird, \& Lancaster, 2005).

\section{METHOD}

\section{Study Selection}

For our analyses, we included six tasks that have been prominent in the interference resolution literature: the go/ no-go task, flanker task, Stroop task, stimulus-response compatibility (SRC) task, Simon task, and stop signal task (all described below). Studies were included only if they reported peaks of activation in standardized coordinate space (Talairach or MNI). Notably absent are tasks used to examine the resolution of proactive interference (e.g., Jonides, Smith, Marshuetz, Koeppe, \& Reuter-Lorenz, 1998), since a review of these data has already been published (Jonides \& Nee, 2006). Furthermore, we do not include the antisaccade task in this mix, because models of this task are already at the single-unit level and our coarse techniques of analysis would be unable to inform this literature further (Munoz \& Everling, 2004). We included neuroimaging studies in which either PET or fMRI was used between 1990 and 2005 and in which normal, healthy, young adults were examined. ${ }^{2}$ Although we recognize that there may be differences between blocked and event-related designs in terms of neural activations, there were insufficient studies to examine each separately. Therefore, we have combined both types of designs in our analyses. Forty-seven studies met our criteria and are listed in Table 1. When possible, we restricted our analyses to correct trials only.

\section{Tasks}

Go/no-go. In the go/no-go task, subjects are required to respond to one stimulus (e.g., the letter "Y") but to withhold a response to another stimulus ("X"). Responses are labeled go trials, whereas trials on which a response is to be withheld are called no-go trials. It has been argued that as the number of go trials preceding a no-go trial increases, a greater prepotent tendency to respond is formed (de Zubicaray et al., 2000; Durston, Thomas, Worden, Yang, \& Casey, 2002; Durston, Thomas, Yang, et al., 2002; Rubia et al., 2001). This prepotent response must be resolved in order to perform properly on no-go trials. Our analyses included contrasts of no-go versus go responses.

Flanker. The flanker task requires a subject to attend to a centrally fixated stimulus while ignoring flanking stimuli (Eriksen \& Eriksen, 1974). In a paradigmatic case, the central stimulus can be a letter (e.g., "H"), which subjects learn to associate with a given response (say, a left keypress). Flanking stimuli can be of three types. First, the flankers can be identical to the imperative stimulus. In this case, both the relevant and the irrelevant stimuli are consistent $(\mathrm{HHH})$. We will refer to this trial type as identical. Flankers can also be different from the central stimulus ("S," for instance), but the participants are instructed to map these stimuli onto the same (say, left) response as the target stimulus (SHS). This trial type is called congruent. Finally, stimuli can differ not only in form from the relevant stimulus, but also in response pairing ("G" mapped onto a right keypress). This is what we call an incongruent trial (GHG). Thus, on identical trials, no conflict is present. On congruent trials, there is stimulus conflict, but not response conflict, and on incongruent trials, there is stimulus, as well as response, conflict (Kornblum, Stevens, Whipple, \& Requin, 1999; van Veen, Cohen, Botvinick, Stenger, \& Carter, 2001; Zhang, Zhang, $\&$ Kornblum, 1999). Our analyses included contrasts of both incongruent versus congruent responses and incongruent versus identical responses. There were insufficient studies to tease these two contrasts apart.

Stimulus-response compatibility. In the SRC paradigm, a subject is required to switch between two 
Table 1

Studies Included in the Meta-Analysis Catalogued by Which Tasks They Included

\begin{tabular}{|c|c|c|c|c|c|c|c|c|c|}
\hline Study & Year & Flanker & Go/No-Go & $\mathrm{SRC}$ & Stroop & Stop Signal & Simon & Contrast & Peaks \\
\hline Adleman et al. & 2002 & & & & $\mathrm{X}$ & & & $\mathrm{I}-\mathrm{N}$ & 3 \\
\hline Banich et al. & 2000 & & & & $\mathrm{X}$ & & & $\mathrm{I}-\mathrm{N}$ & 13 \\
\hline Banich et al. & 2001 & & & & $\mathrm{X}$ & & & $\mathrm{I}-\mathrm{N}$ & 9 \\
\hline Bench et al. & 1993 & & & & $\mathrm{X}$ & & & $\mathrm{I}-\mathrm{N}$ & 13 \\
\hline Bunge et al. & 2002 & $\mathrm{X}$ & & & & & & $\mathrm{I}-\mathrm{C}$ & 10 \\
\hline \multirow[t]{2}{*}{ Carter et al. } & 1995 & & & & $\mathrm{X}$ & & & $\mathrm{I}-\mathrm{C}$ & 9 \\
\hline & & & & & $\mathrm{X}$ & & & $\mathrm{I}-\mathrm{N}$ & 9 \\
\hline Casey et al. & 2002 & & & $\mathrm{X}$ & & & & I-Id & 11 \\
\hline Dassonville et al. & 2001 & & & $\mathrm{X}$ & & & & $\mathrm{I}-\mathrm{C}$ & 14 \\
\hline Derbyshire et al. & 1998 & & & & $\mathrm{X}$ & & & $\mathrm{I}-\mathrm{C}$ & 2 \\
\hline Durston, Thomas, Worden, et al. & 2002 & & $\mathrm{X}$ & & & & & Go/No-go & 9 \\
\hline Durston, Thomas, Yang, et al. & 2002 & & $\mathrm{X}$ & & & & & Go/No-go & 7 \\
\hline \multirow[t]{3}{*}{ Fan et al. } & 2003 & $X$ & & & & & & $\mathrm{I}-\mathrm{C}$ & 14 \\
\hline & & & & & $\mathrm{X}$ & & & $\mathrm{I}-\mathrm{C}$ & 14 \\
\hline & & & & & & & $X$ & $\mathrm{I}-\mathrm{C}$ & 11 \\
\hline Garavan et al. & 1999 & & $\mathrm{X}$ & & & & & Go/No-go & 13 \\
\hline Garavan et al. & 2002 & & $\mathrm{X}$ & & & & & Go/No-go & 16 \\
\hline Hazeltine et al. & 2000 & $\mathrm{X}$ & & & & & & $\mathrm{I}-\mathrm{C}$ & 4 \\
\hline Iacoboni et al. & 1996 & & & $\mathrm{X}$ & & & & $\mathrm{I}-\mathrm{C}$ & 2 \\
\hline Iacoboni et al. & 1998 & & & $X$ & & & & $\mathrm{I}-\mathrm{C}$ & 3 \\
\hline Kiehl et al. & 2000 & & $\mathrm{X}$ & & & & & Go/No-go & 8 \\
\hline Konishi et al. & 1998 & & $\mathrm{X}$ & & & & & Go/No-go & 10 \\
\hline Konishi et al. & 1999 & & $\mathrm{X}$ & & & & & Go/No-go & 2 \\
\hline Leung et al. & 2000 & & & & $\mathrm{X}$ & & & $\mathrm{I}-\mathrm{C}$ & 16 \\
\hline Liddle et al. & 2001 & & $\mathrm{X}$ & & & & & Go/No-go & 23 \\
\hline Liu et al. & 2004 & & & & & & $\mathrm{X}$ & $\mathrm{I}-\mathrm{C}$ & 34 \\
\hline Maclin et al. & 2001 & & & & & & $X$ & $\mathrm{I}-\mathrm{C}$ & 5 \\
\hline Menon et al. & 2001 & & $\mathrm{X}$ & & & & & Go/No-go & 13 \\
\hline Milham et al. & 2001 & & & & $\mathrm{X}$ & & & $\mathrm{I}-\mathrm{N}$ & 7 \\
\hline \multirow{2}{*}{ Milham et al. } & 2002 & & & & $\mathrm{X}$ & & & $\mathrm{I}-\mathrm{N}$ & 22 \\
\hline & & & & & $\mathrm{X}$ & & & $\mathrm{I}-\mathrm{C}$ & 7 \\
\hline Milham et al. & 2003 & & & & $\mathrm{X}$ & & & $\mathrm{I}-\mathrm{N}$ & 23 \\
\hline \multirow[t]{2}{*}{ Milham \& Banich } & 2005 & & & & $\mathrm{X}$ & & & $\mathrm{I}-\mathrm{N}$ & 37 \\
\hline & & & & & $\mathrm{X}$ & & & $\mathrm{I}-\mathrm{C}$ & 22 \\
\hline Pardo et al. & 1990 & & & & $\mathrm{X}$ & & & $\mathrm{I}-\mathrm{C}$ & 13 \\
\hline Paus et al. & 1993 & & & $\mathrm{X}$ & & & & $\mathrm{I}-\mathrm{C}$ & 10 \\
\hline Perlstein et al. & 2003 & & $\mathrm{X}$ & & & & & Go/No-go & 4 \\
\hline Peterson et al. & 1999 & & & & $\mathrm{X}$ & & & $\mathrm{I}-\mathrm{C}$ & 82 \\
\hline \multirow[t]{2}{*}{ Peterson et al. } & 2002 & & & & $\mathrm{X}$ & & & $\mathrm{I}-\mathrm{C}$ & 14 \\
\hline & & & & & & & $\mathrm{X}$ & $\mathrm{I}-\mathrm{C}$ & 14 \\
\hline Ravnkilde et al. & 2002 & & & & $\mathrm{X}$ & & & $\mathrm{I}-\mathrm{C}$ & 8 \\
\hline \multirow[t]{2}{*}{ Rubia et al. } & 2001 & & $\mathrm{X}$ & & & & & Go/No-go & 12 \\
\hline & & & & & & $\mathrm{X}$ & & Stop-Go & 6 \\
\hline Ruff et al. & 2001 & & & & $\mathrm{X}$ & & & $\mathrm{I}-\mathrm{N}$ & 10 \\
\hline Schumacher \& D'Esposito & 2002 & & & $\mathrm{X}$ & & & & $\mathrm{I}-\mathrm{C}$ & 2 \\
\hline Sylvester et al. & 2003 & & & $\mathrm{X}$ & & & & $\mathrm{I}-\mathrm{C}$ & 5 \\
\hline Tamm et al. & 2002 & & $\mathrm{X}$ & & & & & Go/No-go & 4 \\
\hline Taylor et al. & 1994 & & & $\mathrm{X}$ & & & & $\mathrm{I}-\mathrm{C}$ & 3 \\
\hline Taylor et al. & 1997 & & & & $\mathrm{X}$ & & & $\mathrm{I}-\mathrm{N}$ & 12 \\
\hline Ullsperger \& von Cramon & 2001 & $\mathrm{X}$ & & & & & & I-Id & 34 \\
\hline van Veen et al. & 2001 & $\mathrm{X}$ & & & & & & $\mathrm{I}-\mathrm{C}$ & 8 \\
\hline \multirow[t]{3}{*}{ Wager et al. } & 2005 & $\mathrm{X}$ & & & & & & $\mathrm{I}-\mathrm{C}$ & 9 \\
\hline & & & $\mathrm{X}$ & & & & & Go/No-go & 13 \\
\hline & & & & $\mathrm{X}$ & & & & $\mathrm{I}-\mathrm{C}$ & 12 \\
\hline Watanabe et al. & 2002 & & $\mathrm{X}$ & & & & & Go/No-go & 5 \\
\hline \multirow[t]{2}{*}{ Zysset et al. } & 2001 & & & & $\mathrm{X}$ & & & $\mathrm{I}-\mathrm{N}$ & 9 \\
\hline & & & & & $\mathrm{X}$ & & & $\mathrm{I}-\mathrm{C}$ & 4 \\
\hline
\end{tabular}

Note-Contrasts that were reported in the study are indicated in the table (I-C, incongruent-congruent or incompatible-compatible; I-N, incongruent-neutral; I-Id, incongruent-identical). There were a total of 6 flanker studies, contributing 79 peaks; 14 go/no-go studies, contributing 139 peaks; 9 SRC studies, contributing 62 peaks; 12 Stroop (I-N) studies, contributing 158 peaks; 11 Stroop (I-C) studies, contributing 190 peaks; 4 Simon studies, contributing 64 peaks; and 1 stop signal study, contributing 6 peaks.

stimulus-response mappings. One mapping, referred to as compatible, is directly suggested by the stimulus. For example, a typical SRC task might employ arrows as stimuli, in which case a compatible mapping might be a left keypress to an arrow pointing left and a right keypress to an arrow pointing right. An incompatible mapping would require a left keypress to a rightward-pointing arrow and a right keypress to a leftward-pointing arrow. Thus, in the 
incompatible condition, a prepotent response that is suggested by the stimulus and developed by previous compatible responses must be overcome. Our analyses included incompatible minus compatible contrasts.

Stroop. In the Stroop task, subjects must identify the hue in which a word is printed while ignoring the referent of the word. There are three basic types of trials in a typical Stroop task: incongruent, congruent, and neutral. On congruent trials, both the color of the word and the word's referent elicit the same response (e.g., the word "red" printed in red ink). On incongruent trials, the color and referent of the word elicit different responses (the word "green" printed in red ink). Neutral trials may be of several types, but for all neutral trials, the referent of the stimulus does not provide a competing response to the hue (e.g., a series of Xs printed in red, or the word "lot" printed in red). Our analyses included both incongruent minus congruent and incongruent minus neutral contrasts.

Simon. The Simon task is similar to the Stroop task, except that the irrelevant stimulus dimension is spatial. For example, in a paradigmatic Simon task, a relevant stimulus is presented at various spatial locations. The stimulus (say, a colored circle) might appear either to the right or to the left of fixation. The circle is mapped onto a left or a right response (e.g., red-left, blue-right), and subjects must respond to the stimulus while ignoring the potentially distracting spatial placement of the stimulus. It has been found that reaction times are longer when the location of the stimulus is incompatible with the response it elicits (a red circle presented to the right of fixation) than when the location is compatible with the response, due to the resolution of interference caused by the irrelevant spatial dimension of the stimulus. We included incompatible minus compatible contrasts in our analyses.

Stop signal. The stop signal task requires a subject to cease executing a readied response. In a typical stop signal task, a subject is required to respond to a stimulus but to withhold the response if a tone is heard. Varying the onset of the tone, relative to the response, can affect the error rates (responses not withheld) and, thus, the demands on conflict resolution processes. Our analyses include stop versus go responses.

\section{Density Analysis}

We used a data-driven approach to discovering which regions of the brain were most consistently reported in the corpus of studies. To this end, we employed a density analysis technique, which has been successfully used in other meta-analyses (Wager, Jonides, \& Reading, 2004; Wager, Phan, Liberzon, \& Taylor, 2003) and is similar to other voxel-based methods (Fox et al., 2005; Laird et al., 2005). The density technique is similar to the activation likelihood estimate (ALE) method used in some other meta-analyses (Turkeltaub, Eden, Jones, \& Zeffiro, 2002), with one distinction. The density technique examines the spatial consistency among reported peaks and locates brain voxels in which the density of reported peaks exceeds what would be expected by chance. The ALE method assesses the probability that at least one activation peak fell within that voxel by assessing the union of probability values across individ- ual peaks. Although the methods give very similar results, we tested the null hypothesis that the spatial distribution of peaks is random, whereas the ALE method tests the null hypothesis that in no studies was a particular voxel activated.

The density analysis was conducted as follows. We first converted all Talairach peaks into MNI space, in order to have all the data mapped into a common stereotactic space (www.mrc-cbu.cam.ac.uk/Imaging/). Next, we plotted all of the peaks reported in each study onto a canonical brain (avg152T1.img; SPM, Wellcome Department of Imaging Neuroscience, www.fil.ion.ucl.ac.uk/spm/). We included only positive activations, since deactivations are inconsistently reported and difficult to interpret (Phan, Wager, Taylor, \& Liberzon, 2002; Wager et al., 2003). We then calculated a peak density estimate for each of the $2 \times 2 \times$ $2 \mathrm{~mm}$ voxels in the brain; this was defined as the number of $n$ peaks in the analysis contained within a sphere of 10$20 \mathrm{~mm}$ (depending on analysis, described below) surrounding that voxel, divided by the volume of the sphere. Thus, the units of density reported are peaks per cubic millimeter of brain tissue. In order to determine a density distribution for the null hypothesis, we conducted a Monte Carlo simulation with 5,000 iterations per analysis, assuming no systematic spatial organization of the voxels. For each iteration, $n$ points corresponding to the $n$ reported peaks were distributed randomly throughout the gray and white matter of the brain (excluding ventricles and sinus spaces). White matter was included because many reported peaks fall within white matter near white/gray matter boundaries. ${ }^{3}$ The density estimate map across the brain for the peaks as actually reported in the literature was then compared with this null distribution, using a significance threshold of the 95th percentile of the null distribution ( $p<.05$, brainwise, one-tailed). The test statistic is the density of reported peaks in the local area around the voxel being tested, and the Monte Carlo simulation provides $p$ values that reflect how (un)likely it is to obtain the observed density if peaks were actually randomly (uniformly) distributed throughout the brain. A low $p$ value would indicate that the null hypothesis uniform distribution of peaks is unlikely to result in a cluster as dense as the one observed. If the density estimate of a given voxel was significantly greater than what would be expected by the simulated null distribution, we took this voxel to be active for that particular analysis. ${ }^{4}$

Active voxels were grouped into contiguous voxels, using SPM2's contiguity assessment procedures (spm_cluster.m; Wellcome Department of Imaging Neuroscience); that is, if voxels share at least one vertex, they are considered to be part of the same contiguous region. The resulting clusters are reported in Table 2. Localization of these clusters was performed by first converting the clusters back into Talairach space (www.mrc-cbu.cam.ac.uk/Imaging/) and then consulting a standard brain atlas (Talairach \& Tournoux, 1988).

We performed a separate density analysis for each interference contrast: go/no-go, flanker, SRC, and Stroop. Due to the small number of studies in which the Simon and stop signal tasks were investigated, we were unable to perform a density analysis on these tasks. In addition, we performed a density analysis on all of the studies taken 
Table 2

Significant Clusters

\begin{tabular}{|c|c|c|c|c|c|c|}
\hline Task & $x$ & $y$ & $z$ & Voxels & BA & Region \\
\hline \multirow[t]{12}{*}{ All tasks combined } & 2 & 16 & 46 & 552 & $6 / 8 / 32$ & medial frontal/anterior cingulate \\
\hline & 42 & 24 & 28 & 115 & $9 / 8$ & right dorsolateral prefrontal cortex \\
\hline & -40 & 4 & 38 & 76 & 6 & left premotor cortex \\
\hline & -36 & 16 & 4 & 48 & $13 / 45$ & left inferior frontal/insula \\
\hline & -18 & -72 & 42 & 43 & $7 / 19$ & left precuneus \\
\hline & 40 & 6 & 38 & 41 & $6 / 9$ & right dorsolateral prefrontal cortex \\
\hline & 44 & 14 & 8 & 21 & $44 / 13$ & right inferior frontal/insula \\
\hline & 40 & -52 & 42 & 21 & $40 / 7$ & right inferior parietal lobule \\
\hline & -36 & -56 & 44 & 15 & $7 / 39 / 19$ & left inferior parietal lobule \\
\hline & 50 & -44 & 32 & 9 & 40 & right inferior parietal lobule \\
\hline & -40 & 26 & 30 & 7 & 9 & left dorsolateral prefrontal cortex \\
\hline & 34 & 18 & 4 & 5 & 13 & right insula \\
\hline \multirow[t]{9}{*}{ Go/no-go } & 42 & 22 & 24 & 1,143 & $9 / 46 / 13 / 45$ & right dorsolateral prefrontal/inferior frontal \\
\hline & -40 & 32 & 34 & 144 & $9 / 46$ & left dorsolateral prefrontal cortex \\
\hline & 42 & -64 & 34 & 116 & $39 / 40$ & right angular gyrus \\
\hline & 0 & 8 & 54 & 106 & $6 / 32$ & anterior cingulate cortex \\
\hline & -36 & 38 & 20 & 67 & 10 & left middle frontal gyrus \\
\hline & -2 & 26 & 42 & 20 & $32 / 8$ & left anterior cingulate cortex \\
\hline & -44 & 10 & 38 & 12 & 9 & left dorsolateral prefrontal cortex \\
\hline & 38 & -84 & -10 & 10 & $19 / 18$ & right inferior occipital gyrus \\
\hline & 32 & -76 & -10 & 5 & $18 / 19$ & right middle occipital gyrus \\
\hline \multirow[t]{8}{*}{$\mathrm{SRC}$} & 18 & -62 & 48 & 216 & 7 & right precuneus \\
\hline & -8 & 8 & 52 & 31 & 6 & left premotor/supplementary motor area \\
\hline & 0 & 4 & 36 & 10 & 24 & anterior cingulate cortex \\
\hline & -16 & -62 & 48 & 9 & 7 & left precuneus \\
\hline & 10 & 4 & 50 & 9 & 6 & right premotor/supplementary motor area \\
\hline & -22 & 4 & 52 & 8 & 6 & left premotor cortex \\
\hline & -6 & 4 & 40 & 6 & 24 & left anterior cingulate cortex \\
\hline & 6 & -68 & 48 & 5 & 7 & right precuneus \\
\hline \multirow[t]{2}{*}{ Flanker } & 40 & 14 & 28 & 117 & 9 & right dorsolateral prefrontal cortex \\
\hline & 36 & 16 & 20 & 15 & 13 & right insula \\
\hline \multirow[t]{10}{*}{ Stroop } & 0 & 20 & 40 & 1,426 & $6 / 32 / 8$ & medial frontal/anterior cingulate cortex \\
\hline & -42 & 16 & 28 & 1,385 & $9 / 6 / 46 / 8 / 13$ & left dorsolateral prefrontal cortex/inferior frontal \\
\hline & 46 & -48 & 38 & 301 & $40 / 39$ & right inferior parietal lobule \\
\hline & -22 & -64 & 46 & 143 & 7 & left precuneus \\
\hline & 32 & 38 & 22 & 38 & $9 / 10$ & right dorsolateral prefrontal cortex \\
\hline & 12 & -78 & 10 & 26 & $17 / 18$ & right cuneate \\
\hline & 46 & 16 & 30 & 11 & 9 & right dorsolateral prefrontal cortex \\
\hline & 0 & -26 & 6 & 10 & & thalamus \\
\hline & -28 & -66 & 34 & 7 & 19 & left precuneus \\
\hline & 44 & 20 & 22 & 5 & $46 / 9$ & right dorsolateral prefrontal cortex \\
\hline
\end{tabular}

Note-Coordinates are reported in MNI space. Voxels is the area of the region in voxels. Only clusters of 5 voxels or more are reported. BA, Brodmann area.

together. For the individual studies, a density sphere with a 20 -mm radius was used. We used a larger sphere for these analyses because few studies and, therefore, few coordinates were available for each of these tasks. For the analysis that combined all the tasks, we used a smaller region of $10-\mathrm{mm}$ radius, consistent with the size used in previous such meta-analyses (Wager et al., 2003).

\section{RESULTS}

The density analysis performed on the combination of all the tasks produced significant clusters bilaterally in the dorsolateral prefrontal cortex (DLPFC), inferior frontal gyrus (IFG), anterior cingulate cortex (ACC), and posterior parietal cortex (PPC) (see Figure 4). Table 2 summarizes the results.

\section{Individual Task Analyses}

Density analyses performed on each task individually by and large revealed a proper subset of the analysis of the combination of all the tasks (see Table 2 and Figure 3 ).
Go/no-go. For the go/no-go task, the most prominent cluster was in the right DLPFC, extending inferiorly into the right IFG and insula. There were also significant clusters in the left DLPFC, ACC, and right PPC, but these were smaller in extent. There were also small clusters in the right occipital cortex.

Flanker. The flanker task produced a significant cluster in the right DLPFC. Another smaller cluster was found in the right insula, but the extent of the inferior cluster was not nearly the size of the one found in the go/no-go task.

Stimulus-response compatibility. The SRC task produced reliable clusters most prominently in the bilateral PPC, but primarily right lateralized. Clusters were also found in the left supplementary motor area and premotor cortex, as well as in the ACC.

Stroop. Clusters from the Stroop task were primarily left lateralized. There was a large cluster in the left DLPFC that extended inferiorly to the insula. In addition, we found a very large cluster in the medial frontal cortex, 

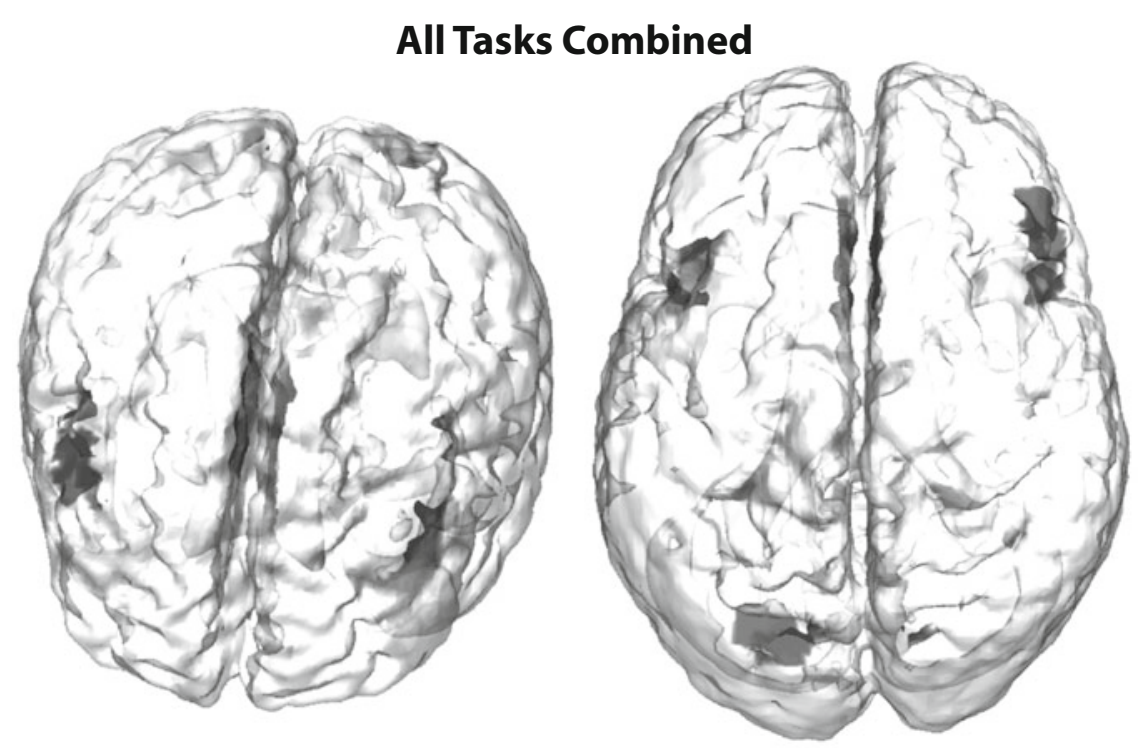

Figure 2. Results of a peak density analysis performed on all of the 47 studies included. Regions are reported in Table 2.

including the ACC. To a lesser extent, there was also a cluster in the left PPC. There were also clusters in the right DLPFC and PPC, but these clusters were much smaller in extent than the ones found in the left hemisphere. Finally, there was also a small cluster in the thalamus.

\section{DISCUSSION}

Despite the seemingly random scatter of activation pictured in Figure 1, our density analysis yielded reliable clusters of activation in many areas that have often been implicated in interference resolution (see Figures 2 and 4). This network of regions may, therefore, be involved in interference resolution in general. However, a look at our individual task analyses reveals that each task reliably activates a subset of these regions. Understanding why each task loads differentially on a distinct subset of regions may be the key to understanding how the brain resolves conflict.

Each task included in this study relies on different methods for inducing cognitive conflict. It is likely that these different forms of conflict act upon different neural mechanisms. For instance, mechanisms that filter out distracting visual information may be useful in the flanker, Stroop, and Simon tasks, in which conflict is produced by competing irrelevant stimuli, but these same mechanisms would not be relevant for the go/no-go task, in which there are no visual distractors. Therefore, examining the differences in the kinds of conflict each task produces and differences in the neural activations that accompany each kind of conflict resolution may shed light on the neural mechanisms underlying interference resolution.

\section{Go/No-Go and Stop Signal}

It is clear that the go/no-go task induces conflict in mechanisms responsible for selecting and executing an appropriate response. As some authors have argued, re- sponse selection and response execution may be distinguishable stages of processing (Rubia et al., 2001; Rubia, Smith, Brammer, \& Taylor, 2003). Therefore, when subjects attempt to overcome the prepotent tendency to respond in the go/no-go task, they may accomplish this either by biasing decision processes toward selecting the appropriate response or by restraining an inappropriate response from being executed and later selecting the appropriate response. In the former case, interference resolution acts upon response selection, and in the latter, it acts upon response execution. At which stage conflict is resolved is likely influenced by the experimental parameters. For instance, as the proportion of go to no-go trials increases, a greater prepotency to respond is formed, which may heavily bias response selection processes in favor of responding, thereby making a subject more reliant upon mechanisms of restraint that act upon response execution (de Zubicaray et al., 2000; Garavan, Ross, \& Stein, 1999). It is likely also that speeded responding would produce a similar effect. Although changes in task parameters would be interesting to explore, we have an insufficient number of studies in which the go/no-go task has been explored to warrant meta-analytic techniques. Therefore, for specifics on how the neural mechanisms underlying interference resolution change as task parameters differ, we rely on single studies.

By far the most reliable activation we found in the go/ no-go task was in the right frontal cortex, including the DLPFC and inferior frontal regions. Somewhat speculatively, we can tease apart what parts of this activation may be due to response selection and what may be due to response execution. One approach is to examine what neural changes occur as the go/no-go task becomes more or less difficult. Presumably, by the logic we have presented, increased difficulty caused by an increased prepotency to respond requires a greater contribution of 
Individual Task Density Analyses
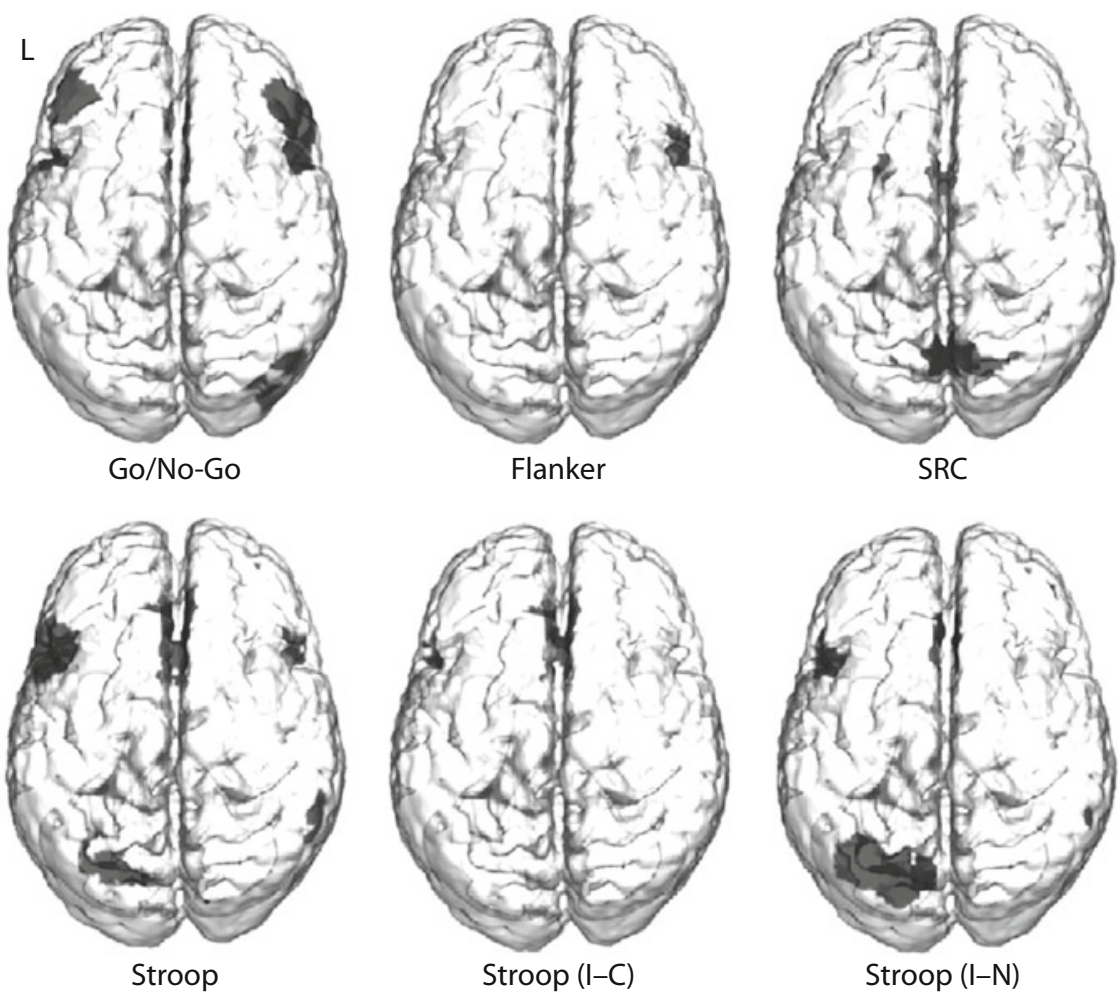

Figure 3. Results of peak density analyses performed separately on the go/no-go, flanker, stimulus-response compatibility (SRC), and Stroop tasks. Also included are separate density analyses performed on studies investigating the incongruent versus congruent Stroop contrast and the incongruent versus neutral Stroop contrast.

resolution mechanisms acting upon response execution. Several studies in which this has been examined have reported that activation in the right IFG increases with increased task difficulty (Durston, Thomas, Worden, et al., 2002; Durston, Thomas, Yang, et al., 2002; Garavan et al., 1999). Another study in which the number of no-go trials was parametrically varied showed that as the number of no-go trials increased, reaction times increased, and errors decreased, suggesting a shift toward more controlled responding (de Zubicaray et al., 2000). This shift in response style was accompanied by an increase in the right DLPFC. Taken together, it appears that in the go/nogo task, right IFG activation underlies resolution during response execution, whereas right DLPFC activation accompanies more controlled resolution, perhaps during the selection of a response.

Although our reasoning is somewhat speculative, it corroborates well the results in the literature concerning the stop signal task. In the stop signal task, the subject must restrain a response when a stop signal occurs, thereby relying solely upon mechanisms that resolve conflict during the execution of a response. Indeed, neuroimaging studies in which the stop signal task has been examined have implicated the right IFG for this kind of interference resolution (Rubia et al., 2001; Rubia et al., 2003). Even stronger evidence for this case is made by lesion evidence. It has been shown that as the size of a lesion in the right IFG increases, performance in the stop signal task gets poorer, thereby implicating the right IFG as a region that is vital to the resolution of conflict during response execution (Aron, Fletcher, Bullmore, Sahakian, \& Robbins, 2003; Aron, Robbins, \& Poldrack, 2004). Although we had an insufficient number of stop signal studies to examine this task separately, the combination of neuroimaging and lesion evidence appears to provide strong support for the notion that the right IFG is heavily involved in resolving conflict due to response execution.

\section{Flanker}

Our examination of the flanker task revealed significant clusters in the right DLPFC and right insula. Notably, these areas overlapped with the frontal areas activated by the go/no-go task, suggesting that these regions may underlie common mechanisms (see Figure 5; Wager et al., 2005). What might these mechanisms be? As was described above, the flanker task can involve stimulus conflict, when the distractor stimuli and target stimuli do not match, and response conflict, when the distractor stimuli are mapped onto a response different from that for the target stimuli. Since the go/no-go task does not include stimulus conflict, the overlapping activations most likely result from response conflict. However, in our discussion 


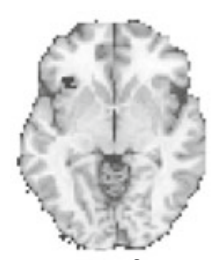

$\mathrm{z}=0$
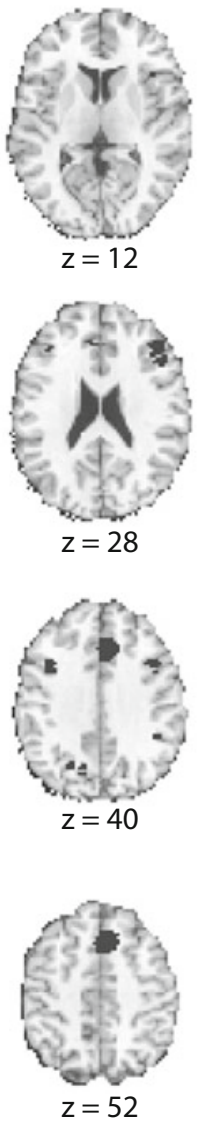
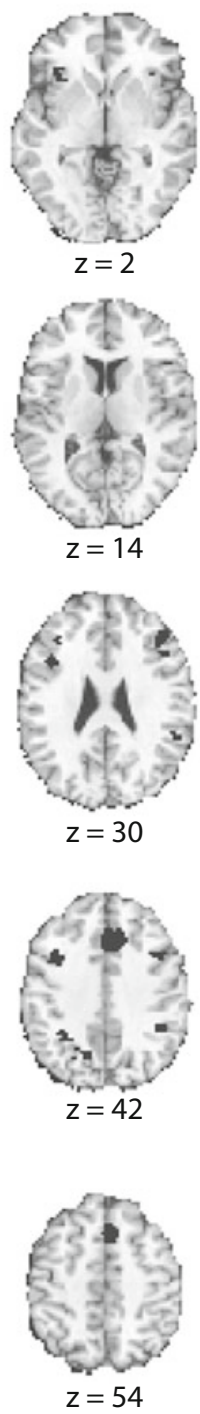
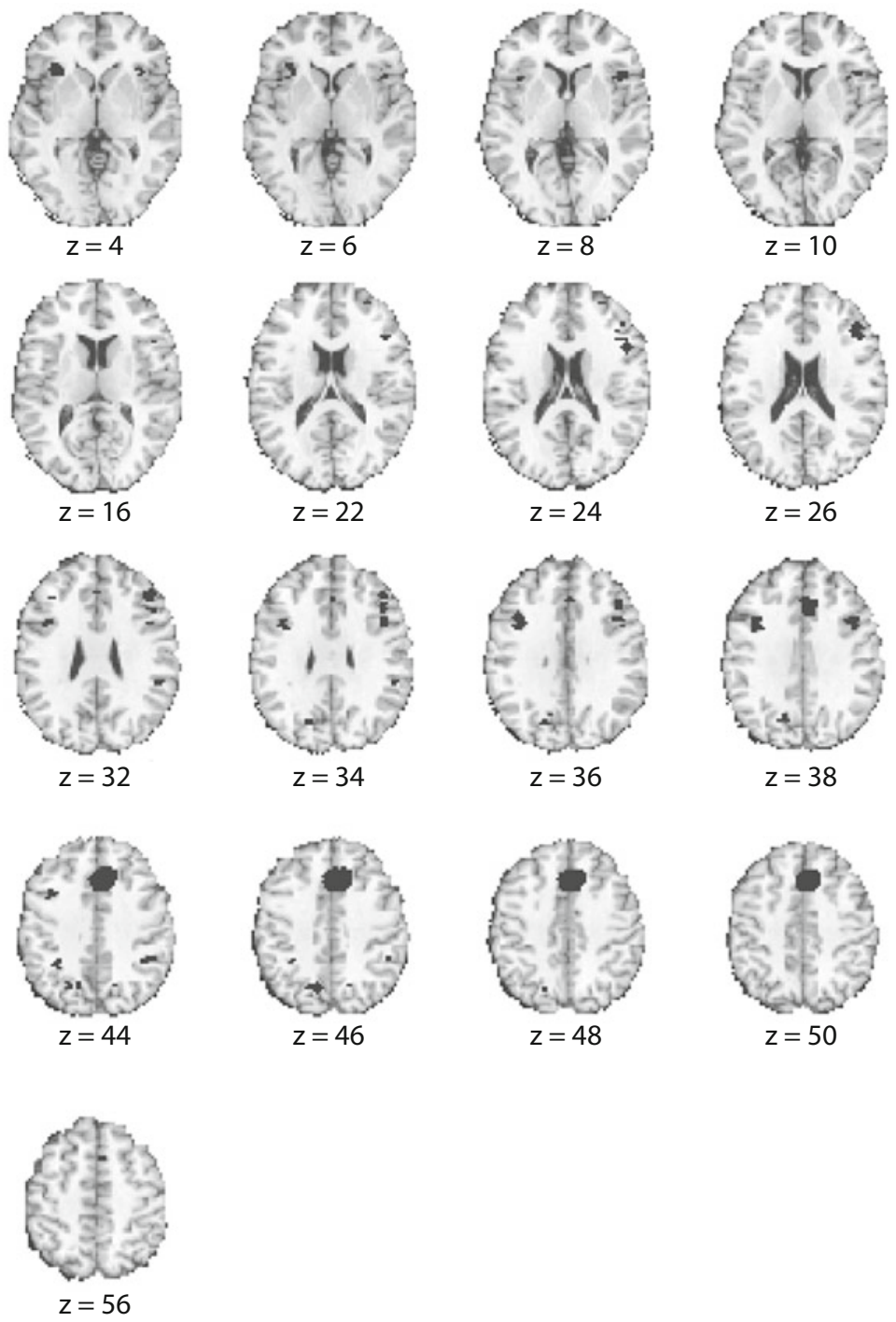

Figure 4. Slice renderings of the peak density analysis performed on all of the 47 studies included.

of the go/no-go task, we delineated two forms of response conflict: response selection conflict and response execution conflict. Furthermore, we implicated right DLPFC activation with resolution of response selection conflict and right inferior frontal activation with the resolution of conflict during response execution. Do these implications match up with the flanker data?

The overlap in the right DLPFC appears to be concordant with the idea that the right DLPFC is involved in interference resolution during response selection. Incongruent flankers bias response selection processes against the appropriate response, thereby requiring resolution processes to overcome this bias. Therefore, in both the flanker and the go/no-go tasks, there is a need to select against a bias toward an inappropriate response. However, the low error rates typically found with the flanker task suggest that there is little need to restrain a response during response execution. Therefore, the inferior frontal overlap appears to be somewhat puzzling.
Whereas the go/no-go task produced a cluster that incorporated both the right IFG and the insula, the inferior frontal cluster in the flanker task was found exclusively in the insula. We did not distinguish the right IFG from the insula in our earlier discussion, mainly because the role of the insula in cognitive tasks remains unclear. One study that compared the go/no-go, flanker, and SRC tasks in the same subjects found common anterior insula activation among the tasks, activation which correlated with behavioral performance (Wager et al., 2005). These authors argued that since all three tasks have resolution processes acting upon response selection in common, the insula is involved somehow in response selection processes. If this is the case, the common insula activation we found in our meta-analysis is orderly, in that it may reflect common mechanisms of response selection in the go/no-go and flanker tasks. However, other authors have argued that the anterior insula is involved in the restraining of inappropriate responses (Garavan et al., 1999). If 
Figure 5. Slice renderings showing the results of the peak density analyses performed on the go/no-go (red), flanker (green), and stimulus-response compatibility (SRC; blue) tasks. Activation overlap between the go/no-go and flanker tasks is depicted in yellow.

this is the case, the insula cluster found here is somewhat problematic.

A closer look into our flanker studies reveals that in one study, a speeded flanker task was used that produced nearly chance accuracy on incongruent trials (Ullsperger \& von Cramon, 2001). The difficulty of this task may have shifted resolution processes to response execution, consistent with our logic for the go/no-go task. Indeed, 11 of the 14 inferior frontal peaks found in our flanker analysis were contributed by this study alone. Therefore, if the inferior frontal region shared by the go/no-go and flanker tasks really does reflect resolution processes acting upon response execution, our flanker result appears to be compatible with this account.

\section{Stimulus-Response Compatibility}

The SRC task is similar to the go/no-go task in that subjects must overcome a prepotent tendency to respond inappropriately in order to perform the task correctly. However, 
the prepotency in the two tasks is somewhat different. In the go/no-go task, the prepotent tendency to respond is due to the immediately preceding context. In other words, a subject has responded to several go trials and is, therefore, likely to respond. In the SRC task, however, the prepotency to respond inappropriately is due not to the immediately preceding context but, rather, to the subject's familiarity with the stimulus in general. For example, it is more natural, on the basis of previously learned responses, to respond to a left arrow with a left response. However, on incompatible trials, subjects must overcome this learned tendency to respond appropriately. Put another way, one major difference between the go/no-go and the SRC tasks is a difference in time scale: In one, a response has been learned due to an immediately preceding context; in the other, a response has been learned over the course of a lifetime. As our data illustrate, these differences result in very different neural patterns.

In contrast to the go/no-go and flanker tasks, which produced predominately frontal activation, the bulk of the activation in the SRC task was in the parietal cortex. The largest cluster was in the left posterior parietal cortex, which included the intraparietal sulcus. Additional clusters were found in the anterior cingulate and premotor/ supplementary motor area.

We can contrast the go/no-go and flanker tasks with the SRC task to help understand these differences. Let us begin with what is common between them. Although a study comparing the go/no-go, flanker, and SRC tasks in the same subjects found several neural regions in common to all (Wager et al., 2005), the only overlap we found was that between the go/no-go and the SRC tasks in the left premotor cortex. This region has been implicated in response selection (Iacoboni, Woods, \& Mazziotta, 1998), and repetitive transcranial magnetic stimulation (rTMS) performed on this region impairs performance on incompatible trials (Praamstra, Kleine, \& Schnitzler, 1999). Therefore, the SRC task may have some component of interference resolution during response selection in common with the go/no-go task.

What is interesting about the neural pattern of results found for the SRC task is that the areas implicated are exactly those regions implicated in a meta-analysis of switching attention (Wager et al., 2004). Indeed, a study in which the SRC task was directly compared with a switching task showed close parallels between the neural signatures of the two tasks (Sylvester et al., 2003). One possibility is that interference resolution in the SRC task is very similar to switching. On incompatible trials, the prepotent response may automatically be elicited, and subjects may need to switch their response set to activate the appropriate response. An alternative but similar proposal is that activation for both switching and the SRC task indicates the need to select among competing stimulus-response associations. However, further testing will be needed to verify whether the type of resolution involved in the SRC task is truly more akin to switching than is the resolution involved in the go/no-go and flanker tasks.

\section{Stroop}

Like the flanker task, the Stroop task involves filtering out distracting irrelevant information that can compete with the appropriate response. However, unlike the flanker task, in which the distractors are adjacent to the imperative stimulus, in the Stroop task, the target and the distractor are different attributes of the same object. In addition, due to the automatic nature of reading the distracting material, an incorrect response is highly prepotent on incongruent trials. Therefore, in the Stroop task, there appears to be a greater demand for selective attention to filter out the distracting information.

In the event that selective attention fails to filter out irrelevant information completely, it is likely that the irrelevant information will bias toward the inappropriate response. How interference resolution proceeds in this case depends on the specifics of the paradigm. It has been argued that the verbal response Stroop task is very different from a manual response Stroop task, due to the verbal task's having an automatic mapping of stimulus to response, whereas the manual case has an arbitrary mapping (MacLeod, 1991). Due to the movement involved in verbal responses, neuroimaging has relied, by and large, on manual responses. A manual response version of the Stroop task most likely relies upon response selection because the subject is required to select among the arbitrary mappings provided by the experimenter. In this case, as with the go/no-go, flanker, and SRC tasks, resolution mechanisms must act upon response selection to favor the correct response in the face of strong competition.

Overall, the Stroop task is similar to the other tasks studied here in its reliance on interference resolution acting upon response selection. However, it differs from the other tasks in its greater need for selective attention. In addition, of the tasks studied here, the Stroop task is the most verbal in nature. Beginning with what is common, the Stroop task overlaps with the go/no-go and flanker tasks in the right DLPFC and with the SRC task in the left premotor/supplementary motor area. Consonant with the idea that the Stroop task shares response selection components with these tasks, all of these regions have been implicated in the resolution of interference during response selection (Bunge, Hazeltine, Scanlon, Rosen, \& Gabrieli, 2002; Durston, Thomas, Worden, et al., 2002; Durston, Thomas, Yang, et al., 2002; Iacoboni et al., 1998; Praamstra et al., 1999). In addition, the Stroop task overlaps both the go/no-go and the SRC tasks in the ACC. This region has been the subject of much debate, mostly centered around its function as a monitor involved in the resolution of response conflict (e.g., Botvinick, Braver, Barch, Carter, \& Cohen, 2001). Once again, this is compatible with the notion that the Stroop task shares response selection components with the other tasks.

Although we failed to find significant overlap, there was a close correspondence in the left posterior parietal cortex (BA 7) between the Stroop task $(-22,-64,46)$ and the SRC task $(-16,-62,48)$. Both tasks share the need to overcome an overly learned prepotent response: in the SRC task, the tendency to respond left to a left-pointing arrow, and in the Stroop task, the tendency to read written words. Earlier, we speculated that resolution in the SRC task may be similar to switching from the prepotent response set to the appropriate response set or selecting 
among stimulus-response associations. It is worth noting that regions that are highly related to switching according to a meta-analysis of switching tasks (the premotor cortex, the intraparietal sulcus, and the anterior cingulate) are present in the Stroop analysis, as they are in the SRC analysis (Wager et al., 2004). Therefore, the Stroop and SRC tasks may share the same sort of switch or stimulusresponse association-related interference resolution.

Other authors have also speculated that the Stroop task shares mechanisms with switching tasks (Brass, Derrfuss, Forstmann, \& von Cramon, 2005; Derrfuss, Brass, Neumann, \& von Cramon, 2005). These authors proposed that both tasks share the need for the updating of task representations. On the basis of a meta-analysis of Stroop and switching tasks, these authors proposed that a region in the left frontal cortex, termed the inferior frontal junction, may mediate this function (Derrfuss et al., 2005). In accordance with this claim, we found a large left frontal cluster in our Stroop analysis that overlapped with this proposed region. We might expect to find similar activation in the SRC task, which would ostensibly require the same task-representation-updating function. However, we did not find reliable clusters in this region in our SRC analyses, although it is possible that this result was due to insufficient power. Perhaps more puzzling is the finding that a separate meta-analysis of 31 switching studies also failed to show reliable clusters in the left inferior frontal junction (Wager et al., 2004), although these authors did find a large left dorsolateral prefrontal region that was more anterior to the inferior frontal junction at a reduced threshold. Further examination will be required to provide a consensus regarding the role of the inferior frontal junction and its relation to the Stroop and switching tasks.

In contrast to the other tasks studied here, the Stroop task is highly left lateralized, most prominently in the left DLPFC and inferior frontal regions. Part of this lateralization may be due to the strongly verbal nature of the Stroop task. Indeed, some authors have implicated left inferior frontal regions in the resolution of verbal conflict (Jonides \& Nee, 2006; Jonides et al., 1998; Leung, Skudlarski, Gatenby, Peterson, \& Gore, 2000). Some of the lateralization may also be due to the greater need for selective attention processes involved in filtering out strongly competitive irrelevant information. Consonant with this idea, one study examined differences during a preparatory period preceding either the Stroop task or the reverse Stroop task where subjects make the easier response of responding to the word rather than the color (MacDonald, Cohen, Stenger, $\&$ Carter, 2000). These authors found greater left DLPFC activation for the Stroop task than for the reverse Stroop task. If we believe that the selective attention demands are greater for the more difficult task, it follows that the left DLPFC may be engaged in preparation for high demands on selective attention. However, this version of the Stroop task involved switching between Stroop and reverse Stroop and produced an abnormally large reverse-Stroop effect, so any conclusions must be drawn with caution.

Perhaps better evidence regarding the involvement of the left DLPFC in selective attention comes from several studies that examined differences when competing stimuli are response eligible versus response ineligible (Liu, Banich, Jacobson, \& Tanabe, 2006; Milham \& Banich, 2005; Milham, Banich, \& Barad, 2003; Milham et al., 2001). In these studies, the subjects learned a mapping of some colors to response keys. These were response-eligible colors. Contrasting with these colors were other colors that did not have mapped responses. Since these items were not available for response, they were response ineligible. Importantly, when used as distracting words, responseeligible words caused both stimulus and response conflict on incongruent trials, whereas response-ineligible words caused only stimulus conflict. Therefore, examining neural responses to response-ineligible trials, in comparison with neutral trials, isolates processes involved in resolving stimulus conflict. Indeed, several studies in which this paradigm has been examined have shown the left DLPFC as being related to resolving stimulus conflict (Liu et al., 2006; Milham \& Banich, 2005; Milham et al., 2003; Milham et al., 2001). This lends support to the idea that the left DLPFC is involved in selective attention.

Unlike in our other tasks, we included both incongruent versus congruent and incongruent versus neutral peaks in our analyses, in that there were many studies in which each contrast was examined. Since we had sufficient data, we also explored whether the incongruent versus congruent contrast differed from the incongruent versus neutral contrast, as some authors have reported (Bench et al., 1993; Carter, Mintun, \& Cohen, 1995; Taylor, Kornblum, Lauber, Minoshima, \& Koeppe, 1997). Indeed, there were significant differences (see Figures 3 and 6). The incongruent minus neutral contrast exhibited far greater left DLPFC and left posterior parietal activation, whereas the incongruent versus congruent contrast revealed larger ACC activation. What this must mean is that congruent trials produce greater activation in the left DLPFC and posterior parietal cortex than do neutral trials and less activation in the ACC than do neutral trials.

Although we are uncertain what exactly to make of these differences, we can provide some speculation. Unlike neutral trials, congruent trials provide a competing response-eligible stimulus (Milham et al., 2002). If the strategy of the subject is to try hard to ignore the irrelevant word, the fact that the word is part of the color set may trigger mechanisms involved in selecting the correct stimulus dimension (color). By this account, we would expect increases in the left DLPFC during congruent trials to filter out potentially distracting information. However, since the responses indicated by both the word and the color are the same, there is no conflict at the response selection stage. Therefore, the reduction in actual response conflict may decrease demand on the ACC. These speculations are supported by a study that examined regions specifically recruited by conflict (incongruent $>$ congruent and neutral trials) and those by competition (incongruent and congruent $>$ neutral) (Milham \& Banich, 2005). In this study, there was greater left dorsolateral prefrontal activity associated with competition (although still significant activation, to a lesser extent, in the left DLPFC for conflict), consonant with the idea that the left DLPFC is involved in both incongruent and congruent trials where 
Figure 6. Slice renderings of the two different Stroop contrasts, including their overlap. I, incongruent; C, congruent; $\mathbf{N}$, neutral.

there is a competing response-eligible word. By contrast, there was greater ACC activity associated with conflict (although a smaller, dissociable region of the ACC produced competition-related activation). These results corroborate well our finding of greater left DLPFC activation for the incongruent minus neutral contrast and greater ACC activation for the incongruent minus congruent contrast.

\section{Putting It Together}

We began by noting a network of regions involved in interference resolution and then interrogated the individual tasks, to attempt to understand the functions that the individual pieces within this network are performing. What is arrived at by piecing together the individual facts is a proposal of separate interference resolution mechanisms act- ing upon different stages of processing. Specifically, from the go/no-go and stop signal data, it appears as though right inferior frontal regions are heavily involved in restraining an inappropriate response during response execution. Commonalities in the go/no-go, flanker, SRC, and Stroop tasks implicate the right DLPFC and ACC in interference resolution during response selection. For cases such as the Stroop and SRC tasks, the intraparietal sulcus and premotor cortex may also be involved during response selection, perhaps as a means of switching from inappropriate to appropriate response sets or selecting among competing stimulus-response associations. Finally, the Stroop data point to the left DLPFC for resolution of stimulus conflict, perhaps via selective attention mechanisms, and to the left inferior frontal regions for resolution of verbal conflict. 
We are quick to note that these are merely hypotheses borne out of the meta-analysis, rather than conclusions. Each of these hypotheses needs further testing.

To bolster these hypotheses, we performed a logistic regression in order to investigate whether resolution of interference at different stages of processing would predict activation in a given region. We coded each study by whether the task included resolution during response execution, response selection, or stimulus encoding and examined whether these predictors explained activation in the right IFG, left IFG, left DLPFC, right DLPFC, and ACC. In addition, since we hypothesized that resolution of verbal information may involve the left IFG, we performed a separate logistic regression on the left IFG, using verbal conflict as a predictor (Jonides \& Nee, 2006; Jonides et al., 1998; Leung et al., 2000; Nelson, Reuter-Lorenz, Sylvester, Jonides, \& Smith, 2003). The results supported our hypotheses. Stimulus conflict significantly predicted activation in the left DLPFC (Wald $=5.58, p=.018$ ) and the left IFG (Wald $=6.9, p=.008)$. Verbal conflict also predicted left IFG activation (Wald $=6.5, p=.01$ ). Finally, conflict during response execution marginally predicted activation in the right IFG (Wald $=3.27, p=.07$ ). We note that conflict during response selection did not significantly predict activation in any region, but this is most likely due to the fact that all tasks other than the one stop signal task included in our meta-analysis elicit conflict during response selection and, therefore, this predictor had insufficient variance to explain activation.

These results are consistent with the idea that different neural regions are responsible for the resolution of interference at different stages of processing. However, we recognize that there may be other ways to organize interference resolution processes as well. Some authors have carefully distinguished several different forms of conflict, each of which may require its own dissociable resolution mechanisms (Kornblum, Hasbroucq, \& Osman, 1990; Kornblum et al., 1999; Zhang et al., 1999). Unfortunately, most neuroimaging studies of interference resolution confound several of these forms of conflict, thereby making it difficult to distinguish among them. Further investigation is needed to determine whether interference resolution mechanisms can be more finely dissociated than we suggest here.

\section{Mechanisms of Interference Resolution}

We have implicated several regions as important in the resolution of interference, but we have not speculated how this conflict is resolved. Resolution may proceed via the facilitation of appropriate information, inhibition of inappropriate information, a combination of the two, or some other strategy, such as switching response sets (Hasher, Zacks, \& May, 1999; MacLeod, Dodd, Sheard, Wilson, $\&$ Bibi, 2003). We believe that the extant data cannot yet penetrate this question, so we remain agnostic as to how interference is resolved.

\section{Relation to Other Work}

Several other meta-analyses have been performed to look for consistencies among neuroimaging data (Cabeza
\& Nyberg, 2000; Duncan \& Owen, 2000; Johnson et al., 2005; Wager et al., 2004; Wager \& Smith, 2003). For example, Duncan and Owen demonstrated that regions of the frontal cortex, including the ACC and the dorsolateral and ventrolateral prefrontal cortices, were recruited by diverse cognitive demands not exclusive to conflict. Their analyses of 19 studies produced little if any discernible dissociation among the various tasks studied when all peaks were plotted on the same canonical brain. Similar to their analysis, combining all of our studies produced the same network of regions. However, when each task was interrogated individually, we found dissociations within this network. Why did we find dissociations when Duncan and Owen did not?

Figure 7 shows a plot of all of the peaks included in this study, color coded by the particular task contributing the peak. From this figure, it is difficult to discern dissociable patterns. Examining the data in this way demonstrates the clear need for clustering techniques. It is possible that with the inclusion of more studies and a clustering technique, dissociable patterns may emerge from the tasks studied by Duncan and Owen (2000).

Other meta-analyses in which particular tasks have been looked at have shown regions overlapping with the regions we find here. As was mentioned earlier, a meta-analysis of switching tasks produced clusters in the parietal and premotor cortex similar to the areas we found for the SRC and Stroop tasks, indicating that resolution for these tasks may have a commonality with switching (Wager et al., 2004). Furthermore, a meta-analysis of working memory tasks implicated several frontal and parietal regions found here (Wager \& Smith, 2003). This corroborates findings linking working memory with susceptibility to interference (de Fockert, Rees, Frith, \& Lavie, 2001; Engle, Kane, \& Tuholski, 1999; Hester, Murphy, \& Garavan, 2004; Kane, Bleckley, Conway, \& Engle, 2001; Kane \& Engle, 2003; Kim, Kim, \& Chun, 2005). Working memory tasks often require not only the active maintenance of information, but also the filtering out of distraction and selecting among representations for both maintenance and response processes. Consonant with the idea that the left DLPFC is important for selective attention, increasing demand on the left DLPFC by imposing a working memory load increases interference from irrelevant perceptual material (de Fockert et al., 2001). In addition, increasing demand on the right DLPFC by increasing working memory load decreases go/no-go performance, perhaps due to shared components of response selection (Hester et al., 2004). These results suggest a close tie between working memory and interference resolution.

Finally, refreshing, or bringing to focus an item in mind, recruits the bilateral frontal cortex, ACC, and PPC (Johnson et al., 2005). Refreshing verbal material preferentially activates left inferior frontal regions, whereas no other refresh-related region demonstrates a verbal preference (Johnson et al., 2005). The left inferior frontal gyrus may be important in selecting the appropriate verbal material to refresh (Jonides \& Nee, 2006; Thompson-Schill, D'Esposito, Aguirre, \& Farah, 1997). This verbal selection role is consonant with our data demonstrating that the left 
Figure 7. Peaks from all 47 studies plotted in a canonical brain, color coded by task. GNG, go/no-go; SRC, stimulus-response compatibility.

IFG is needed for interference resolution of verbal conflict. It is likely that other commonalities between regions found here and in refreshing also reflect selection of various sorts of representations. Further work is needed to examine the relation between interference resolution and refreshing.

\section{CONCLUSIONS}

Examining the combination of many tasks that involve interference resolution revealed that a network including the bilateral DLPFC, inferior frontal regions, the PPC, and the ACC may underlie the resolution of conflict. We hypothesize that separating functions by the stage of processing at which conflict is resolved may provide a useful framework for understanding interference resolution.
Although future research will be needed to test these hypotheses and add further to our understanding of how each region performs interference resolution, our data suggest that the right IFG is important during response execution, the right DLPFC and ACC during response selection, and the left DLPFC during stimulus encoding. In addition, switching-related regions in the intraparietal sulcus and premotor cortex may contribute to some forms of interference resolution.

\section{AUTHOR NOTE}

This material is based on work supported by the National Science Foundation under Grant 0520992 and by a National Science Foundation Graduate Research Fellowship. Correspondence concerning this article should be addressed to D. E. Nee, Department of Psychology, Univer- 
sity of Michigan, 530 Church St., Ann Arbor, MI 48109-1043 (e-mail: dnee@umich.edu).

\section{REFERENCES}

Adleman, N. E., Menon, V., Blasey, C. M., White, C. D., WarsofSKY, I. S., Glover, G. H., \& Reiss, A. L. (2002). A developmental fMRI study of the Stroop color-word task. NeuroImage, 16, 61-75.

Aron, A. R., Fletcher, P. C., Bullmore, E. T., Sahakian, B. J., \& Robisns, T. W. (2003). Stop-signal inhibition disrupted by damage to right inferior frontal gyrus in humans. Nature Neuroscience, $\mathbf{6}$, 115-116.

Aron, A. R., Robbins, T. W., \& Poldrack, R. A. (2004). Inhibition and the right inferior frontal cortex. Trends in Cognitive Sciences, $\mathbf{8}$, 170-177.

Banich, M. T., Milham, M. P., Atchley, R., Cohen, N. J., Webb, A., WszaleK, T., ET AL. (2000). fMRI studies of Stroop tasks reveal unique roles of anterior and posterior brain systems in attentional selection. Journal of Cognitive Neuroscience, 12, 988-1000.

Banich, M. T., Milham, M. P., Jacobson, B. L., Webb, A., Wszalek, T., Cohen, N. J., \& Kramer, A. F. (2001). Attentional selection and the processing of task-irrelevant information: Insights from fMRI examinations of the Stroop task. Progress in Brain Research, 134, 459-470.

Bench, C. J., Frith, C. D., Grasby, P. M., Friston, K. J., Paulesu, E., Frackowiak, R. S. J., \& Dolan, R. J. (1993). Investigations of the functional anatomy of attention using the Stroop test. Neuropsychologia, 31, 907-922.

Botvinick, M. M., Braver, T. S., Barch, D. M., Carter, C. S., \& Cohen, J. D. (2001). Conflict monitoring and cognitive control. Psychological Review, 108, 624-652.

Brass, M., Derrfuss, J., Forstmann, B., \& von Cramon, D. Y. (2005). The role of the inferior frontal junction area in cognitive control. Trends in Cognitive Sciences, 9, 314-316.

Bunge, S. A., Hazeltine, E., Scanlon, M. D., Rosen, A. C., \& GaBRIELI, J. D. E. (2002). Dissociable contributions of prefrontal and parietal cortices to response selection. NeuroImage, 17, 1562-1571.

CABEZA, R., \& NYBERG, L. (2000). Imaging cognition II: An empirical review of 275 PET and fMRI studies. Journal of Cognitive Neuroscience, 12, 1-47.

Carter, C. S., Mintun, M., \& Cohen, J. D. (1995). Interference and facilitation effects during selective attention: An H215O PET study of Stroop task performance. NeuroImage, 2, 264-272.

Casey, B. J., Thomas, K. M., Davidson, M. C., Kunz, K., \& Franzen, P. L. (2002). Dissociating striatal and hippocampal function developmentally with a stimulus-response compatibility task. Journal of Neuroscience, 22, 8647-8652.

Dassonville, P., Lewis, S. M., Zhu, X. H., Ugurbil, K., Kim, S. G., \& AsHe, J. (2001). The effect of stimulus-response compatibility on cortical motor activation. NeuroImage, 13, 1-14.

de Fockert, J. W., Rees, G., Frith, C. D., \& Lavie, N. (2001). The role of working memory in visual selective attention. Science, 291, 1803-1806.

Derbyshire, S. W. G., Vogt, B. A., \& Jones, A. K. P. (1998). Pain and Stroop interference tasks activate separate processing modules in anterior cingulate cortex. Experimental Brain Research, 118, 52-60.

Derrfuss, J., Brass, M., Neumann, J., \& von Cramon, D. Y. (2005). Involvement of the inferior frontal junction in cognitive control: Metaanalyses of switching and Stroop studies. Human Brain Mapping, 25, 22-34.

de Zubicaray, G. I., Andrew, C., Zelaya, F. O., Williams, S. C. R., \& DumanoIR, C. (2000). Motor response suppression and the prepotent tendency to respond: A parametric fMRI study. Neuropsychologia, 38, 1280-1291.

Duncan, J., \& Owen, A. M. (2000). Common regions of the human frontal lobe recruited by diverse cognitive demands. Trends in Neurosciences, 23, 475-483.

Durston, S., Thomas, K. M., Worden, M. S., Yang, Y., \& Casey, B. J. (2002). The effect of preceding context on inhibition: An event-related fMRI study. NeuroImage, 16, 449-453.

Durston, S., Thomas, K. M., Yang, Y., UluĞ, A. M., Zimmerman, R. D., \& CASEY, B. J. (2002). A neural basis for the development of inhibitory control. Developmental Science, 5, F9-F16.
EngLe, R. W., Kane, M. J., \& TuHOLSKI, S. W. (1999). Individual differences in working memory capacity and what they tell us about controlled attention, general fluid intelligence, and functions of the prefrontal cortex. In A. Miyake \& P. Shah (Eds.), Models of working memory: Mechanisms of active maintenance and executive control (pp. 102-134). Cambridge: Cambridge University Press.

EriKsen, B. A., \& EriKsen, C. W. (1974). Effects of noise letters upon the identification of a target letter in a nonsearch task. Perception \& Psychophysics, 16, 143-149.

Fan, J., Flombaum, J. I., McCandliss, B. D., Thomas, K. M., \& PosNER, M. I. (2003). Cognitive and brain consequences of conflict. NeuroImage, 18, 42-57.

Fox, P. T., Laird, A. R., \& Lancaster, J. L. (2005). Coordinate-based voxel-wise meta-analysis: Dividends of spatial normalization. Report of a virtual workshop. Human Brain Mapping, 25, 1-5.

Garavan, H., Ross, T. J., Murphy, K., Roche, R. A. P., \& Stein, E. A. (2002). Dissociable executive functions in the dynamic control of behavior: Inhibition, error detection, and correction. NeuroImage, 17, 1820-1829.

Garavan, H., Ross, T. J., \& Stein, E. A. (1999). Right hemispheric dominance of inhibitory control: An event-related functional MRI study. Proceedings of the National Academy of Sciences, 96, 8301-8306.

HASHER, L., ZACKS, R. T., \& MAY, C. P. (1999). Inhibitory control, circadian arousal, and age. In D. Gopher \& A. Koriat (Eds.), Attention and performance XVII: Cognitive regulation of performance. Interaction of theory and application (pp. 653-675). Cambridge, MA: MIT Press.

Hazeltine, E., Poldrack, R., \& Gabrieli, J. D. E. (2000). Neural activation during response competition. Journal of Cognitive Neuroscience, 12, 118-129.

Hester, R., Murphy, K., \& Garavan, H. (2004). Beyond common resources: The cortical basis for resolving task interference. NeuroImage, 23, 202-212.

IACOBONI, M., Woods, R. P., \& MAZziotTa, J. C. (1996). Brain-behavior relationships: Evidence from practice effects in spatial stimulusresponse compatibility. Journal of Neurophysiology, 76, 321-331.

Iacoboni, M., Woods, R. P., \& MazziotTa, J. C. (1998). Bimodal (auditory and visual) left frontoparietal circuitry for sensorimotor integration and sensorimotor learning. Brain, 121, 2135-2143.

Johnson, M. K., Raye, C. L., Mitchell, K. J., Greene, E. J., CunNINGHAM, W. A., \& SANisLow, C. A. (2005). Using fMRI to investigate a component process of reflection: Prefrontal correlates of refreshing a just-activated representation. Cognitive, Affective, \& Behavioral Neuroscience, 5, 339-361.

JonIDES, J., \& NEE, D. E. (2006). Brain mechanisms of proactive interference in working memory. Neuroscience, 139, 181-193.

Jonides, J., Smith, E. E., Marshuetz, C., Koeppe, R. A., \& ReuterLORENZ, P. A. (1998). Inhibition in verbal working memory revealed by brain activation. Proceedings of the National Academy of Sciences, 95, 8410-8413.

Kane, M. J., Bleckley, M. K., Conway, A. R., \& Engle, R. W. (2001). A controlled-attention view of working-memory capacity. Journal of Experimental Psychology: General, 130, 169-183.

KANE, M. J., \& ENGLE, R. W. (2003). Working-memory capacity and the control of attention: The contributions of goal neglect, response competition, and task set to Stroop interference. Journal of Experimental Psychology: General, 132, 47-70.

KieHL, K. A., Liddle, P. F., \& Hopfinger, J. B. (2000). Error processing and the rostral anterior cingulate: An event-related fMRI study. Psychophysiology, 37, 216-223.

Kiм, S.-Y., KIM, M.-S., \& ChUN, M. M. (2005). Concurrent working memory load can reduce distraction. Proceedings of the National Academy of Sciences, 102, 16524-16529.

Konishi, S., Nakajima, K., Uchida, I., Kikyo, H., Kameyama, M., \& MiYashita, Y. (1999). Common inhibitory mechanism in human inferior prefrontal cortex revealed by event-related functional MRI. Brain, 122, 981-991.

Konishi, S., Nakajima, K., Uchida, I., Sekihara, K., \& Miyashita, Y. (1998). No-go dominant brain activity in human inferior prefrontal cortex revealed by functional magnetic resonance imaging. European Journal of Neuroscience, 10, 1209-1213.

Kornblum, S., Hasbrouce, T., \& Osman, A. (1990). Dimensional overlap: Cognitive basis for stimulus-response compatibility-a model and taxonomy. Psychological Review, 97, 253-270. 
Kornblum, S., Stevens, G. T., Whipple, A., \& Requin, J. (1999). The effects of irrelevant stimuli: 1 . The time course of stimulus-stimulus and stimulus-response consistency effects with Stroop-like stimuli, Simon-like tasks, and their factorial combinations. Journal of Experimental Psychology: Human Perception \& Performance, 25, 688-714.

Kramer, A. F., Humphrey, D. G., Larish, J. F., Logan, G. D., \& Strayer, D. L. (1994). Aging and inhibition: Beyond a unitary view of inhibitory processing in attention. Psychology \& Aging, 9, 491-512.

Laird, A. R., McMillan, K. M., Lancaster, J. L., Kochunov, P., Turkeltaub, P. E., Pardo, J. V., \& Fox, P. T. (2005). A comparison of label-based review and ALE meta-analysis in the Stroop task. Human Brain Mapping, 25, 6-21.

Leung, H.-C., Skudlarski, P., Gatenby, J. C., Peterson, B. S., \& Gore, J. C. (2000). An event-related functional MRI study of the Stroop color word interference task. Cerebral Cortex, 10, 552-560.

Liddle, P. F., KieHL, K. A., \& Smith, A. M. (2001). Event-related fMRI study of response inhibition. Human Brain Mapping, 12, 100-109.

LiU, X., Banich, M. T., Jacobson, B. L., \& Tanabe, J. L. (2004). Common and distinct neural substrates of attentional control in an integrated Simon and spatial Stroop task as assessed by event-related fMRI. NeuroImage, 22, 1097-1106.

LiU, X., Banich, M. T., Jacobson, B. L., \& Tanabe, J. L. (2006). Functional dissociation of attentional selection within PFC: Response and non-response related aspects of attentional selection as ascertained by fMRI. Cerebral Cortex, 16, 827-834.

MacDonald, A. W., III, Cohen, J. D., Stenger, V. A., \& Carter, C. S. (2000). Dissociating the role of the dorsolateral prefrontal and anterior cingulate cortex in cognitive control. Science, 288, 1835-1838.

MACLEOD, C. M. (1991). Half a century of research on the Stroop effect: An integrative review. Psychological Bulletin, 109, 163-203.

Macleod, C. M., Dodd, M. D., Sheard, E. D., Wilson, D. E., \& BIBI, U. (2003). In opposition to inhibition. In B. H. Ross (Ed.), The psychology of learning and motivation: Advances in research and theory (Vol. 43, pp. 163-214). San Diego: Academic Press.

Maclin, E. L., Gratton, G., \& Fabiani, M. (2001). Visual spatial localization conflict: An fMRI study. NeuroReport, 12, 3633-3636.

Menon, V., Adleman, N. E., White, C. D., Glover, G. H., \& Reiss, A. L. (2001). Error-related brain activation during a go/nogo response inhibition task. Human Brain Mapping, 12, 131-143.

Milham, M. P., \& Banich, M. T. (2005). Anterior cingulate cortex: An fMRI analysis of conflict specificity and functional differentiation. Human Brain Mapping, 25, 328-335.

Milham, M. P., BANich, M. T., \& Barad, V. (2003). Competition for priority in processing increases prefrontal cortex's involvement in topdown control: An event-related fMRI study of the Stroop task. Cognitive Brain Research, 17, 212-222.

Milham, M. P., Banich, M. T., Webb, A., Barad, V., Cohen, N. J., Wszalek, T., \& Kramer, A. F. (2001). The relative involvement of anterior cingulate and prefrontal cortex in attentional control depends on nature of conflict. Cognitive Brain Research, 12, 467-473.

Milham, M. P., Erickson, K. I., Banich, M. T., Kramer, A. F., WebB, A., WszaleK, T., \& Cohen, N. J. (2002). Attentional control in the aging brain: Insights from an fMRI study of the Stroop task. Brain \& Cognition, 49, 277-296.

Munoz, D. P., \& Everling, S. (2004). Look away: The anti-saccade task and the voluntary control of eye movement. Nature Reviews Neuroscience, 5, 218-228.

Nelson, J. K., Reuter-Lorenz, P. A., Sylvester, C. Y., Jonides, J., \& SMith, E. E. (2003). Dissociable neural mechanisms underlying response-based and familiarity-based conflict in working memory. Proceedings of the National Academy of Sciences, 100, 11171-11175.

Pardo, J. V., Pardo, P. J., Janer, K. W., \& Raichle, M. E. (1990). The anterior cingulate cortex mediates processing selection in the Stroop attentional conflict paradigm. Proceedings of the National Academy of Sciences, 87, 256-259.

Paus, T., Petrides, M., Evans, A. C., \& Meyer, E. (1993). Role of the human anterior cingulate cortex in the control of oculomotor, manual, and speech responses: A positron emission tomography study. Journal of Neurophysiology, 70, 453-469.

Perlstein, W. M., Dixit, N. K., Carter, C. S., Noll, D. C., \& Cohen, J. D. (2003). Prefrontal cortex dysfunction mediates deficits in work- ing memory and prepotent responding in schizophrenia. Biological Psychiatry, 53, 25-38

Peterson, B. S., Kane, M. J., Alexander, G. M., Lacadie, C., Skudlarski, P., Leung, H. C., ET AL. (2002). An event-related functional MRI study comparing interference effects in the Simon and Stroop tasks. Cognitive Brain Research, 13, 427-440.

Peterson, B. S., Skudlarski, P., Gatenby, J. C., Zhang, H. P., AnDerson, A. W., \& Gore, J. C. (1999). An fMRI study of Stroop word-color interference: Evidence for cingulate subregions subserving multiple distributed attentional systems. Biological Psychiatry, 45, 1237-1258.

Phan, K. L., Wager, T., Taylor, S. F., \& Liberzon, I. (2002). Functional neuroanatomy of emotion: A meta-analysis of emotion activation studies in PET and fMRI. Neurolmage, 16, 331-348.

Praamstra, P., Kleine, B. U., \& Schnitzler, A. (1999). Magnetic stimulation of the dorsal premotor cortex modulates the Simon effect. NeuroReport, 10, 3671-3674.

Ravnkilde, B., Videbech, P., Rosenberg, R., Gjedde, A., \& Gade, A. (2002). Putative tests of frontal lobe function: A PET-study of brain activation during Stroop's test and verbal fluency. Journal of Clinical \& Experimental Neuropsychology, 24, 534-547.

Rubia, K., Russell, T., Overmeyer, S., Brammer, M. J., Bullmore, E. T., Sharma, T., ET AL. (2001). Mapping motor inhibition: Conjunctive brain activations across different versions of go/no-go and stop tasks. NeuroImage, 13, 250-261.

Rubia, K., Smith, A. B., Brammer, M. J., \& Taylor, E. (2003). Right inferior prefrontal cortex mediates response inhibition while mesial prefrontal cortex is responsible for error detection. NeuroImage, $\mathbf{2 0}$ 351-358.

Ruff, C. C., Woodward, T. S., Laurens, K. R., \& Liddle, P. F. (2001). The role of the anterior cingulate cortex in conflict processing: Evidence from reverse Stroop interference. NeuroImage, 14, 1150-1158.

Schumacher, E. H., \& D'Esposito, M. (2002). Neural implementation of response selection in humans as revealed by localized effects of stimulus-response compatibility on brain activation. Human Brain Mapping, 17, 193-201.

Shilling, V. M., Chetwynd, A., \& Rabbitt, P. M. (2002). Individual inconsistency across measures of inhibition: An investigation of the construct validity of inhibition in older adults. Neuropsychologia, $\mathbf{4 0}$, 605-619.

Stroop, J. R. (1935). Studies of interference in serial verbal reactions. Journal of Experimental Psychology, 18, 643-662.

Sylvester, C.-Y. C., Wager, T. D., Lacey, S. C., Hernandez, L., Nichols, T. E., Smith, E. E., \& Jonides, J. (2003). Switching attention and resolving interference: fMRI measures of executive functions. Neuropsychologia, 41, 357-370.

Talairach, J., \& Tournoux, P. (1988). Co-planar stereotaxic atlas of the human brain: 3-dimensional proportional system. An approach to cerebral imaging (M. Rayport, Trans.). Stuttgart: Thieme.

Tamm, L., Menon, V., \& Reiss, A. L. (2002). Maturation of brain function associated with response inhibition. Journal of the American Academy of Child \& Adolescent Psychiatry, 41, 1231-1238.

Taylor, S. F., Kornblum, S., Lauber, E. J., Minoshima, S., \& Koepre, R. A. (1997). Isolation of specific interference processing in the Stroop task: PET activation studies. NeuroImage, 6, 81-92.

Taylor, S. F., Kornblum, S., Minoshima, S., Oliver, L. M., \& Koeppe, R. A. (1994). Changes in medial cortical blood flow with a stimulusresponse compatibility task. Neuropsychologia, 32, 249-255.

Thompson-Schill, S. L., D’Esposito, M., Aguirre, G. K., \& Farah, M. J. (1997). Role of left inferior prefrontal cortex in retrieval of semantic knowledge: A reevaluation. Proceedings of the National Academy of Sciences, 94, 14792-14797.

Turkeltaub, P. E., Eden, G. F., Jones, K. M., \& ZefFiro, T. A. (2002). Meta-analysis of the functional neuroanatomy of single-word reading: Method and validation. NeuroImage, 16, 765-780.

Ullsperger, M., \& von Cramon, D. Y. (2001). Subprocesses of performance monitoring: A dissociation of error processing and response competition revealed by event-related fMRI and ERPs. NeuroImage, 14, 1387-1401.

van Veen, V., Cohen, J. D., Botvinick, M. M., Stenger, V. A., \& CARTER, C. S. (2001). Anterior cingulate cortex, conflict monitoring, and levels of processing. NeuroImage, 14, 1302-1308. 
WAGER, T. D., Jonides, J., \& READING, S. (2004). Neuroimaging studies of shifting attention: A meta-analysis. NeuroImage, 22, 1679-1693.

Wager, T. D., Phan, K. L., Liberzon, I., \& TAYlor, S. F. (2003). Valence, gender, and lateralization of functional brain anatomy in emotion: A meta-analysis of findings from neuroimaging. NeuroImage, 19, 513-531.

Wager, T. D., \& Sмith, E. E. (2003). Neuroimaging studies of working memory: A meta-analysis. Cognitive, Affective, \& Behavioral Neuroscience, 3, 255-274.

Wager, T. D., Sylvester, C. Y., Lacey, S. C., Nee, D. E., Franklin, M., \& Jonides, J. (2005). Common and unique components of response inhibition revealed by fMRI. NeuroImage, 27, 323-340.

Watanabe, J., Sugiura, M., Sato, K., Sato, Y., Maeda, Y., Matsue, Y., ET AL. (2002). The human prefrontal and parietal association cortices are involved in no-go performances: An event-related fMRI study. NeuroImage, 17, 1207-1216.

Zhang, H. H., Zhang, J., \& Kornblum, S. (1999). A parallel distributed processing model of stimulus-stimulus and stimulus-response compatibility. Cognitive Psychology, 38, 386-432.

Zysset, S., Muller, K., Lohmann, G., \& von Cramon, D. Y. (2001). Color-word matching Stroop task: Separating interference and response conflict. NeuroImage, 13, 29-36.

\section{NOTES}

1. It is clear from this figure that certain peaks seem to lie outside of the canonical brain (avg152T1.img; SPM, Wellcome Department of Imaging Neuroscience, www.fil.ion.ucl.ac.uk/spm/). In order to plot all of the reported peaks into a single brain, coordinates that were reported in Talairach space were converted to MNI space (www.mrc-cbu.cam. ac.uk/Imaging/). It is possible either that there are some imperfections with the transformation tool or that some authors incorrectly reported that their coordinates were in Talairach space when they were actually in MNI space, causing the transformation to move these peaks outside of the canonical brain.

2. Several studies included also looked at patient, younger, or older populations. Data included in our analyses consisted only of those data extracted from normal, healthy young adults.

3 . We acknowledge that although some reported peaks fall within white matter or gray matter/white matter boundaries, peaks are more likely to fall within gray matter. Therefore, it may not be appropriate to distribute simulated peaks uniformly across gray and white matter. However, the assumption of uniform distribution across gray and white matter greatly simplifies the analysis. Some studies do report peaks relatively deep in white matter, whether due to spatial imprecision, neurovascular translation in the BOLD effect, or some other factors. The inclusion of white matter makes the tests here slightly less conservative than they would be if we included only some white matter (near gray matter structures, for example) or only gray matter, but the difference is relatively small. Indeed, analyses that excluded white matter produced very similar results (as did simulations that increased the number of Monte Carlo simulations to 10,000 ). Therefore, we deem that this method offers a reasonable approximation.

4. We realize that using peaks ignores the volume and significance level of activation. In addition, our resolution is limited by the density radius, and the nonconformity of peaks may derive from variations in smoothing function images. As a result, we merely propose hypotheses from our data, rather than drawing conclusions. However, we point out that this and similar techniques have provided useful results in several published studies (e.g., Phan et al., 2002; Turkeltaub et al., 2002; Wager et al., 2004; Wager et al., 2003).

(Manuscript received July 6, 2006 ; revision accepted for publication December 21, 2006.) 